\title{
Functional Analysis of the Promoter of a Glycosyl Hydrolase Gene Induced in Resistant Sinapis alba by Alternaria brassicicola
}

\author{
Madhuvanti Chatterjee, Mrinmoy Mazumder, and Debabrata Basu
}

Division of Plant Biology, Bose Institute, P1/12 C. I. T. Scheme VIIM, Kolkata-700054, West Bengal, India. Accepted for publication 20 February 2013.

\begin{abstract}
Chatterjee, M., Mazumder, M., and Basu, D. 2013. Functional analysis of the promoter of a glycosyl hydrolase gene induced in resistant Sinapis alba by Alternaria brassicicola. Phytopathology 103:841-850.

A putative family 3 glycosyl hydrolase $(G H)$ gene showed significant differential expression in resistant Sinapis alba, compared with the susceptible Brassica juncea, as part of the initial responses during interaction with the necrotroph Alternaria brassicicola. To understand the mechanism of induction, the promoter was isolated and deletion analysis carried out. All the promoter fragments were fused with the $\beta$ glucuronidase gene and the expressions were studied in stable $B$. juncea

the expression of the promoter showed the presence of functional abscisic acid (ABA)-, jasmonic acid (JA)-, and salicylic acid (SA)-responsive cis elements. Interestingly, the promoter was found to be induced in both $S$. alba and B. juncea upon challenge with A. brassicicola but, in $S$. alba, SA had an inhibitory effect on the pathogen-induced expression of the gene whereas, in B. juncea, SA did not have any negative effect. Therefore, the SA-mediated inhibition in $S$. alba indicates that the induction is probably through JA or ABA signaling. The difference in the mechanism of induction of the same promoter in the resistant and susceptible plants is probably due to the differential hormonal responses initiated upon challenge with A. brassicicola.
\end{abstract} transgenics and transiently transformed Nicotiana tabacum. Analysis of
Plants are constantly exposed to a vast array of pathogens throughout their lifetime. An encounter between a plant and a pathogen often results in the immediate triggering of pathogenspecific plant defense arsenal to prevent pathogen invasion and ensure the plant's survival in an incompatible interaction. However, delayed and inappropriate responses of plants against the invading pathogen during compatible interactions allow the successful growth of the pathogen, with the plants often succumbing to death. The resistance mechanisms that become operational after an encounter with the pathogen are either the resistance-gene mediated gene-for-gene resistance or the more complex and widespread nonhost resistance, in which an entire species shows resistance toward a pathogen by virtue of being a "nonhost" $(7,18,23,24,30)$.

Alternaria brassicicola, a necrotrophic fungal pathogen that causes the devastating Black spot disease in members of the family Brassicaceae, is responsible for huge yield losses of oilseed mustard. The absence of the resistance mechanism in the oilseed germplasm makes the crop vulnerable toward this pathogen. In contrast, Arabidopsis Col-0 and the white mustard Sinapis alba exhibit nonhost resistance against this pathogen. Therefore, the elucidation and understanding of the mechanism of resistance that is operational in these plants is extremely vital for developing strategies to combat this disease.

Alteration of the primary metabolic processes of plants is an extremely important feature that determines the fitness of plants against pathogens. The onset of the defense phenomena puts tremendous pressure on the plants' resources, and the plants have

Corresponding author: D. Basu; E-mail addresses:

debu@bosemain.boseinst.ac.in; debu_basu2002@yahoo.co.in; debu@jcbose.ac.in

* The $\boldsymbol{e}$-Xtra logo stands for "electronic extra" and indicates that the online version contains seven supplemental figures and one supplemental table. Figures 1 and 9 appear in color online.

http://dx.doi.org/10.1094/PHYTO-11-12-0303-R

(C) 2013 The American Phytopathological Society adapted several means to cope with this pressure. The development of necrotic and chlorotic areas during pathogen infection leads to a decrease in photosynthesis $(43,48)$. The gradual transition of the source tissue to the sink tissues occurs frequently to meet the extra demand of assimilates $(5,6,9,26,53)$. Sugars have emerged as an important component of the plant-signaling pathways during the early defense responses $(8,29)$. Genes involved in carbohydrate metabolism form an important part of the cascade of genes associated with plant defense (37). Recent studies have shown that there is a significant overlap in the sugar metabolizing genes, such as amylases, $\beta$-1,3-glucanases, glucosyl transferases, hexokinase, and chitinases, which are upregulated during stresses such as senescence and pathogen attack $(13,52)$.

Glycosyl hydrolases (GHs) comprise a vast assembly of enzymes that hydrolyze the glycosidic bond between carbohydrates or between carbohydrate and noncarbohydrate moieties. GHs are grouped into various families based on amino acid sequence similarities (25). These proteins perform diverse functions in both plants and microbes. Many pathogenesis-related (PR) proteins belong to the $G H$ group. $G H$ family 17 and families 18 and 19 , which contain the $\beta-1,3$ glucanases and chitinases, respectively, form an important part of the defense arsenal of plants against fungal pathogens $(33,46,54)$.

$\beta$-Glucosidases (EC 3.2.1.21) are GHs that hydrolyze the $\beta$-Oglycosidic bond at the anomeric carbon of a glucose moiety at the nonreducing end of a carbohydrate or glycoside molecule. They are grouped with the family 1 and $3 \mathrm{GH}$ proteins. The family 3 $\beta$-glucosidases are involved in various important housekeeping physiological functions, such as degradation, the assimilation of exogenous glycosides, and cell wall recycling. In maize, a family 3 exo- $\beta$-D-glucanase, involved in the turnover of $\beta-1,3-$ and $\beta$-1,4-glucans and closely associated with the developmental responses, was purified from and immunolocalized to the cell wall (27). Although some recent studies have reported the involvement of these enzymes during plant defense response, relatively little is known about the role of this group during hostmicrobe interactions (17). A family $3 G H$ gene was found to be 
upregulated in resistant $S$. alba but not in susceptible Brassica juncea during the interaction with $A$. brassicicola in a previous study (20).

The induction of these classes of genes indicates that a reprogramming of the plant transcriptome occurs under biotic stress such as pathogen and insect attack as well as under abiotic stress such as salt, drought, and cold stresses $(15,32,44,45)$. Differences in the expression patterns of the genes, including the plant defense genes, are a result of the architecture of the promoters, which are dissimilar in the number, order, and type of regulatory elements present and because of their differential recognition by the trans-acting factors $(35,38-40)$. The extremely precise regulation of the transcriptome is mainly governed by the perception of the early signals followed by activation of downstream effector molecules. The phytohormones act as mediator molecules, playing important roles in modulating the transcriptome $(4,41)$.

In the present study, we have studied the induction mechanism of a putative family $3 \mathrm{GH}$ gene that shows a significant amount of differential expression in the resistant $S$. alba plants compared with susceptible $B$. juncea plants during the interaction with the necrotroph $A$. brassicicola. The isolation and detailed functional analysis of the upstream region of the $S$. alba $G H$ gene was performed to determine the mechanisms regulating the induction of the gene. Deletion analysis of the promoter showed the presence of functional phytohormone-responsive cis-elements in the upstream region which were recognized differentially in $S$. alba and B. juncea after encounter with A. brassicicola.

\section{MATERIALS AND METHODS}

Plant growth and treatment. $S$. alba and $B$. juncea plants were grown and inoculated with $A$. brassicicola as previously described by Ghose et al. (20). B. juncea, S. alba, and Nicotiana tabacum plants were treated with phytohormones individually, and the control plants were treated similarly but without the addition of the hormones. Salicylic acid (SA) (at both 1 and $5 \mathrm{mM}$ ) was sprayed on the leaves of the plants. In $S$. alba, the fungal inoculation was performed after $3 \mathrm{~h}$ of SA treatment. A $150-\mu \mathrm{M}$ methyl jasmonate (MeJA) solution in $0.1 \%$ ethanol was painted on the leaves, and the plants were covered with plastic bags. A 5-mM abscisic acid (ABA) solution was sprayed on the leaves. The leaves were collected after $12 \mathrm{~h}$ in all hormone treatments.

Quantitative real-time reverse-transcription polymerase chain reaction analysis of gene transcripts. Total RNA was isolated from the leaves of S. alba, B. juncea, and N. tabacum using the NucleoSpin RNA Plant kit (Macherey-Nagel, Duren, Germany), as described in the specified protocol. Contaminating traces of genomic DNA were removed using RQ1 RNase-free DNase (Promega Corp., Madison, WI). The first-strand cDNA was synthesized from total RNA using SuperScript III Reverse Transcriptase (Invitrogen, CA) and the oligo d(T) primer. The primers for the $P R I$ and the Allene oxide synthase $(A O S)$ genes were designed from the Brassica database (www.brassicadb.org) after a BLAST X search with the corresponding Arabidopsis homologues, AT2G14610.1 and AT5G42650.1, respectively. All the primers used were checked by reverse-transcription polymerase chain reaction (RT-PCR) for the amplification of a single band, followed by cloning and sequencing. The primers with the corresponding accession numbers of the genes are listed in Supplemental Table 1. PCR cycling conditions comprised an initial denaturation step at $94^{\circ} \mathrm{C}$ for $2 \mathrm{~min}$, followed by 40 cycles at $94^{\circ} \mathrm{C}$ for $35 \mathrm{~s}, 56$ to $58^{\circ} \mathrm{C}$ for $45 \mathrm{~s}$, and $72^{\circ} \mathrm{C}$ for $1 \mathrm{~min}$. The ACTIN gene was used as an internal reference, the quantitative real-time PCR was performed in an Applied Biosystems 7500 machine using the SYBR Green I master mix, and calculations were done as previously described by Ghose et al. (20) and Livak and Schmittgen (31).
Isolation of the promoter and cloning of the complete coding region of the $\boldsymbol{G H}$ gene. Genomic DNA from $S$. alba was isolated using the DNeasy Plant Mini Kit (Qiagen, Hilden, Germany). Promoter isolation was performed according to the protocol of the Genome Walker Universal Kit (Clontech, CA). Adaptors were ligated to the DNA after digestion with StuI, EcoRV, PvuII, and DraI restriction enzymes (Fermentas, PA) to generate "genomic libraries". The StuI library, after amplification with the Advantage 2 Polymerase mix (Clontech) using the adaptorspecific primer AP1 and the gene-specific primer GH RO (Supplemental Table 1 ), yielded an $\approx 3.5$-kb fragment. After digestion with SalI (site present in the adaptor only) and EcoRI, the band yielded $\approx 2$ - and $\approx 1.5$-kb fragments, which were then subcloned in $\operatorname{pBLUESCRIPTSK}( \pm)$ vector. The $\approx 2$-kb fragment was sequenced and scanned with the PLACE software (http://www.dna.affrc. go.jp) to identify cis-elements in the upstream region.

For 3' rapid amplification of cDNA ends (RACE), the cDNA from 24-h-postinoculation (hpi) leaf samples of $S$. alba was synthesized using the $3^{\prime}$ RACE-cDNA synthesis (CDS) primer (Clontech) and subsequently amplified with the gene-specific forward primer GH RF and the adaptor-specific reverse primer PCRIIA. The $\approx 900$-bp amplified fragment was eluted from the gel, cloned, and sequenced (Supplemental Figure 2). The fulllength CDS of the $G H$ gene was amplified from the $S$. alba cDNA 24 hpi using the forward primer $\mathrm{GH} \mathrm{CF}$, designed from the $5^{\prime}$ portion of the gene sequence obtained through genome walking, and the reverse primer $\mathrm{GH} \mathrm{CR}$, designed from the sequence obtained using 3' RACE. Advantage 2 Polymerase mix (Clontech) was used for the PCR. The $\approx 1.8-\mathrm{kb}$ fragment (Supplemental Figure 3) was eluted from the gel, cloned, and sequenced (42).

Vector construction for stable and transient transformation experiments. For stable transformation, the promotor of the $S$. alba glycosyl hydrolase $(\mathrm{GH})$ gene $(\mathrm{PGH})$ promoter (1,096 bp) and the D1 (780 bp) and D2 (387 bp) deletions were amplified using the forward primers GTF1, GTF2, and GTF3, respectively, and the common reverse primer GTR. The respective clones, without any changes in the nucleotide sequence, were fused with the $\beta$-glucuronidase $(G U S)$ gene at the BamHI and NcoI sites in the binary vector pCAMBIA 1301 by replacing the Cauliflower mosaic virus (CaMV) 35S promoter. The chimeric vectors were transformed into Agrobacterium LBA4404 for plant transformation.

The vectors for the transient transformation experiments were prepared in the following manner. The CSG-MP, $\mathrm{F}_{1} \mathrm{SG}-\mathrm{MP}$, and $\mathrm{F}_{2} \mathrm{SG}-\mathrm{MP}$ fusion constructs of the $G H$ promoter and the $-46-\mathrm{bp}$ minimal CaMV 35S promoter were generated by PCR ligation. In the first step using the forward primer PF, which contained $25 \mathrm{bp}$ ( -412 to $-388 \mathrm{bp}$ ) of the GH promoter along with $15 \mathrm{bp}$ of the CaMV 35S minimal promoter, and the reverse primer RMP, which had the 46-bp CaMV 35S minimal promoter and a NcoI site, a double-stranded fusion product was generated using PCR. The amplified product was called PF-MP and was purified for further use. In the second step to fuse the different deletions of the $G H$ promoter with the $46-\mathrm{bp} 35 \mathrm{~S}$ minimal promoter, the primers GTF1 ( $-1,096 \mathrm{bp}), \mathrm{F}_{1} \mathrm{~F}$ (-780 bp), and $\mathrm{F}_{2} \mathrm{~F}$ (-607 bp), each with a $5^{\prime}$ overhanging Bam $\mathrm{HI}$ site, and the reverse primer MP-R, containing a NcoI site, were used for the PCR amplification of a mix containing the eluted PGH promoter and the PF-MP fragments as templates. The final amplification products, consisting of the CSG-MP, $\mathrm{F}_{1} \mathrm{SG}-\mathrm{MP}$, and $\mathrm{F}_{2} \mathrm{SG}-\mathrm{MP}$ fragments, were cloned into the pGEMT-easy vector (Promega Corp.) and sequenced. The chimeric promoters containing the minimal CaMV 35S promoter were cloned in the BamHI and NcoI sites in the pCAMBIA 1301 vector, which were then transformed into Agrobacterium LBA4404 and used for transient transformation in N. tabacum.

Plant transformation. The protocol for the stable transformation of B. juncea was performed as described by Dutta et al. (16), with slight modifications. Explants prepared from the hypo- 
cotyl region of 6-day-old seedlings were placed in the regeneration medium (RM) (Murashige-Skoog [MS] medium supplemented with 6,benzylaminopurine [2 mg/liter] and 2,4-dichlorophenoxyacetic acid [0.05 mg/liter]) for $24 \mathrm{~h}$. After co-cultivation for $48 \mathrm{~h}$ with Agrobacterium, containing the different constructs, and subsequent washing, the explants were placed in fresh RM supplemented with cefotaxim at $300 \mathrm{mg} / \mathrm{liter}$, hygromycin at 10 $\mathrm{mg} /$ liter, and $20 \mu \mathrm{M} \mathrm{AgNO}_{3}$ for 10 days. Explants were transferred to fresh RM medium with cefotaxim at $200 \mathrm{mg} / \mathrm{liter}$, hygromycin at $25 \mathrm{mg} / \mathrm{liter}$, and $20 \mu \mathrm{m} \mathrm{AgNO}_{3}$. Regenerated plantlets were transferred to the MS basal medium with hygromycin to finally produce stable transgenic plants. Transgenics were confirmed by genomic PCR using the GUS- and promoterspecific primers (Supplemental Figures 4, 5, and 6). Transgenics were analyzed for inducible GUS expression after various treatments by histochemical assay according to Dutta et al. (16). Transient transformation was performed by agroinfiltration in the N. tabacum leaves according to the protocol of Pruss et al. (36). On average, eight infiltrations were performed per leaf. Total RNA from three such leaves was isolated for real-time RT-PCR analysis of each set. Real-time RT-PCR was performed taking four independent biological replicates and the N. tabacum ACTIN gene as the internal reference.

\section{RESULTS}

Disease progression in the resistant and susceptible plants. In susceptible $B$. juncea plants, the pathogen-induced symptoms of rapid chlorosis and necrosis appeared within $48 \mathrm{~h}$ of inoculation with A. brassicicola spores. However, in resistant $S$. alba, the symptoms started to develop from 72 hpi with a more restricted lesion formation compared with B. juncea (Fig. 1). The infected $B$. juncea plants died within a week following the
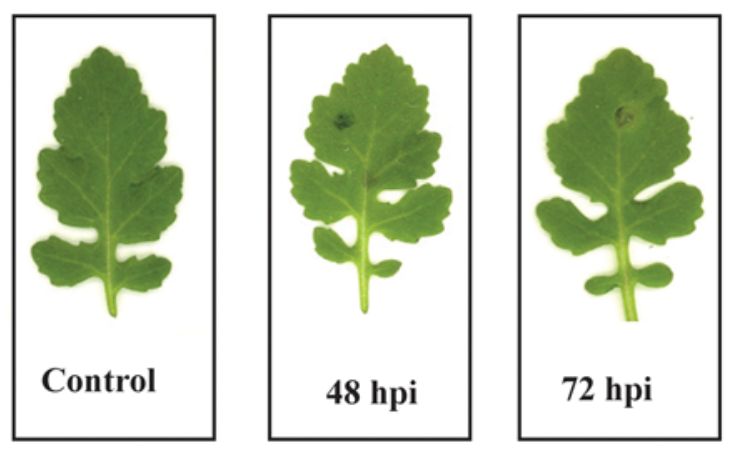

Sinapis alba
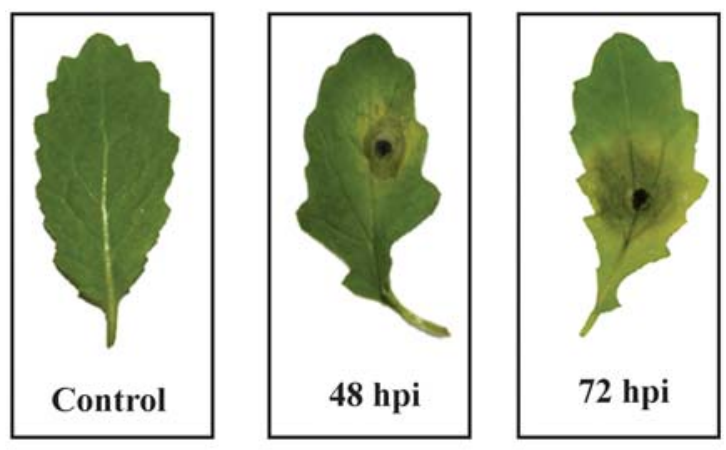

\section{Brassica juncea}

Fig. 1. Comparison of disease progression in the leaves of resistant Sinapis alba and susceptible Brassica juncea 48 and $72 \mathrm{~h}$ postinoculation (hpi) with Alternaria brassicicola spores.
A. brassicicola infection, whereas the $S$. alba plants survived the pathogen attack by shedding the infected leaves and subsequently paying the penalty of growth retardation (20).

Differential expression of a $\boldsymbol{G H}$ gene in $S$. alba and $B$. juncea on interaction with $A$. brassicicola. A previous functional genomic study (cDNA-amplified fragment length polymorphism [AFLP]) in our laboratory helped to identify some sugarmetabolizing genes, such as a GH3 $\beta$-D-glucan exohydrolase, a hexokinase, and a family $17 \mathrm{GH}$ (accession numbers DQ988573, DQ988619, and DQ988595, respectively), that were upregulated in $S$. alba compared with $B$. juncea (20).

The $\beta$-D-glucan exohydrolase $(G H)$, which belongs to the vast multigene family of GHs that have various functions in plant development and during plant defense, was considered for further study. The expression of the $G H$ gene was monitored in the two plants using real-time RT-PCR after challenge with A. brassicicola. In $S$. alba, the gene remained upregulated up to $72 \mathrm{hpi}$, with slight reduction in expression at $48 \mathrm{hpi}$. In contrast, the $B$. juncea $G H$ gene remained approximately at the basal level with little change in its expression level (Fig. 2).

Isolation of the upstream element of the $G H$ gene of $S$. alba. To understand the induction mechanism of the $G H$ gene, the promoter was isolated. There is no information available in the database and, therefore, the promoter was isolated using the strategy of Genome Walking. Amplification of the genomic libraries (construction procedure is mentioned in the Materials and Methods section) was performed using an adaptor-specific forward primer (AP1) and a gene-specific reverse primer (GH RO). The single 3.5-kb band amplified from the StuI library was subcloned after digestion with the SalI and EcoRI enzymes for sequence analysis (Supplemental Figure 1). BLASTX analysis of the 2,038-bp SalI-EcoRI fragment using the TAIR database (http://www.arabidopsis.org) showed the presence of a 450-bp region downstream from the ATG start codon of the $G H$ gene along with a 1,588-bp upstream region. Analysis of the 450-bp region revealed that a 283 -bp sequence showed $90 \%$ identity with the

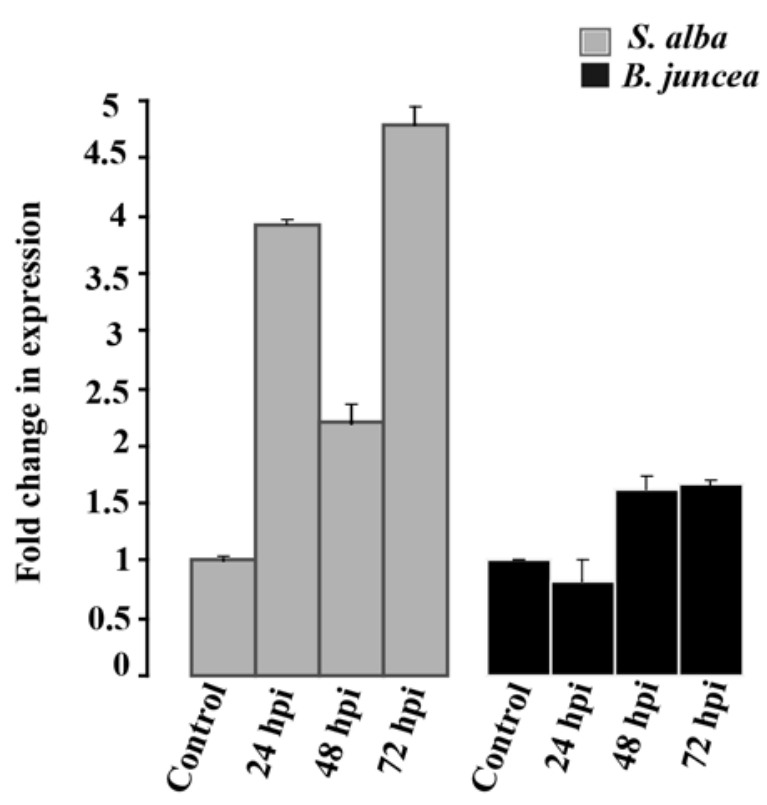

Fig. 2. Expression analysis of the glycosyl hydrolase $(G H)$ gene in Sinapis alba and Brassica juncea plants at different hours postinoculation (hpi) with Alternaria brassicicola spores using real-time reverse-transcription polymerase chain reaction analysis. Leaf samples of $S$. alba and B. juncea at the respective time points, inoculated with only water droplets without spores, were taken as controls. In all treatments, relative changes of expression of the gene were plotted with respect to the respective controls (values one) which, therefore, has been represented only once. Bars represent mean \pm standard error of three biological replicates. 
Arabidopsis thaliana GH homologue, AT3G47000.1 (the same homologue that showed $90 \%$ identity with the cDNA-AFLP fragment), whereas a 167-bp region did not show any homology, indicating that it probably was an intron (data not shown). A 1,096-bp region upstream of the ATG of the $G H$ gene was used to further study the promoter. The sequence has been submitted to GenBank (accession number JQ013782).

Computational analysis of the 1,096-bp upstream sequence using the PLACE software showed the presence of several putative cis-acting elements previously identified for playing important roles in mediating phytohormone responses during several biotic and abiotic stresses in different plant system. The distributions of a few important motifs are shown in Table 1.

Isolation and characterization of the $G H$ gene of $S$. alba. The full-length coding region of the $S$. alba $G H$ gene was obtained. The $3^{\prime}$ portion of the gene, beyond the region present in the cDNA-AFLP fragment, was obtained using $3^{\prime}$ RACE. The $\approx 900$-bp fragment obtained by the amplification of the first-strand cDNA from 24-hpi leaves of $S$. alba using the gene-specific primer GH RF and PCRIIA (Supplemental Figure 2) was cloned and sequenced. The BLASTX analysis showed that the $3^{\prime}$ region of the $G H$ gene, consisting of 271 amino acids, and the $3^{\prime}$ untranslated region had been obtained. Maximum identity was found with the A. thaliana homologue AT3G47000.1.

To obtain the complete coding region, RT-PCR was performed using the 24-hpi $S$. alba cDNA with the forward primer ( $\mathrm{GH} \mathrm{CF}$ ) designed from the beginning of the coding sequence, which was obtained from the previous genome walking experiment, and the reverse primer (GH CR) designed from the $3^{\prime}$ end obtained by RACE (Supplemental Figure 3). The full-length coding region of
$1,830 \mathrm{bp}$ starting from the ATG to the stop codon TAA that consisted of a total of 609 amino acids was obtained (submitted under GenBank accession number JQ013779). BLASTX analysis in the National Center for Biotechnology Information database (http://www.ncbi.nlm.nih.gov) showed that the complete coding region shared $89 \%$ homology with the A. thaliana homologue AT3G47000.1. Alignment of the sequence of the complete coding region with the $5^{\prime}$ region of the $G H$ gene showed that the $167-\mathrm{bp}$ region, obtained by genome walking, was an intron. The $\beta-D-$ glucan exohydrolase of $S$. alba belongs to family 3 of the $\mathrm{GH}$ family of proteins and contains a conserved aspartic acid residue and an active site that spans the region of amino acids 277 to 294, based on the PROSITE scan in the EXPASY portal. The protein was shown to be localized within the plasma membrane by the PSORT prediction software.

Functional analysis of the $S$. alba $G H$ promoter in transgenic B. juncea. To identify the important cis elements imparting phytohormone-mediated inducibility to the $S$. alba $G H$ promoter, the 1,096-bp upstream sequence was fused with the GUS gene in the binary vector pCAMBIA 1301 (PGH-GUS) and used for the generation of stable transgenic lines by Agrobacterium-mediated transformation. S. alba did not respond well to regeneration in vitro and the frequency of transformation was very low. On the other hand, B. juncea, which is very amiable to tissue culture, was selected for the purpose of raising stable transgenic plants. This provided us with the added advantage of studying the induction mechanism of the same promoter, upon challenge with Alternaria brassicicola, in the susceptible background. In this process, 12 hygromycin-resistant plants of the T0 generation were selected. Among these, three lines which grew well and showed positive

TABLE 1. Distribution of the phytohormone-responsive motifs in the upstream region of the Sinapis alba glycosyl hydrolase gene (GH) gene as shown in the PLACE database ${ }^{\mathrm{a}}$

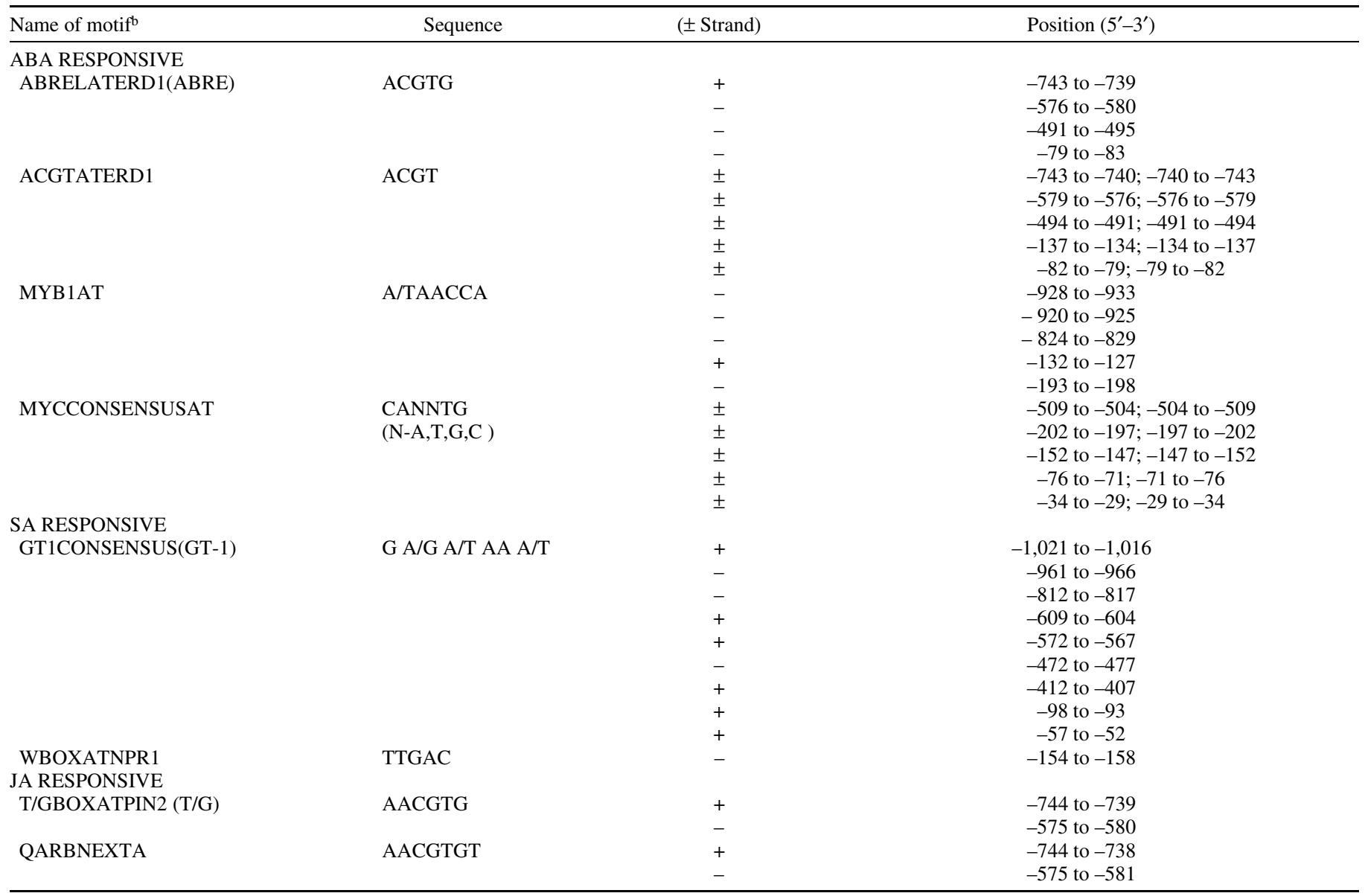

a Positions shown are relative to the translation start site, ATG.

b Abscisic acid (ABA), jasmonic acid (JA), and salicylic acid (SA). 
PCR amplification with the primers of the $G U S$ gene and the $G H$ promoter-specific primers and showed GUS staining on challenge with A. brassicicola were selected for further analysis. PCR amplification of two of these lines is shown in Supplemental Figure 4. In this context, it is to be mentioned that the preferential GUS staining in the veins of the leaves of B. juncea at 24 hpi (Fig. 3A ii) indicated that the promoter was capable of inducing the expression of the GUS gene in the susceptible $B$. juncea background on challenge with A. brassicicola. GUS expression in the transgenic $B$. juncea leaves was also observed in the presence of 5 mM SA (Fig. 3A iii).

Dissection of the $A$. brassicicola-mediated induction mechanism of the $\boldsymbol{G H}$ gene. As mentioned earlier, the $G H$ gene was highly upregulated in $S$. alba upon challenge with A. brassicicola. The induction of the $G H$ promoter was ascertained in transgenic $B$. juncea by quantifying the expression of the GUS reporter gene, placed under the PGH promoter in one of the transgenic $B$. juncea lines, by real-time RT-PCR after $A$. brassicicola challenge. The promoter was induced even in the susceptible $B$. juncea background at 24 and 48 hpi with $A$. brassicicola spores. However, the induction was much less in comparison with $S$. alba at 24 hpi (Fig. 4).

To understand the phytohormone-mediated signaling responsible for the induction of the $G H$ gene in $S$. alba, the expression was studied after exogenous application of MeJA, ABA, and SA. The gene was upregulated upon treatment with $150 \mu \mathrm{M}$ MeJA and $5 \mu \mathrm{M}$ ABA. In contrast, $1 \mathrm{mM}$ SA was not capable of inducing the gene. However, the induction of the gene by $5 \mathrm{mM} \mathrm{SA}$ indicates that the induction of the promoter by SA is concentration dependent (Fig. 5). The GUS expression in the PGH-GUS transgenic plants was enhanced in the presence of $150 \mu \mathrm{M}$ MeJA,

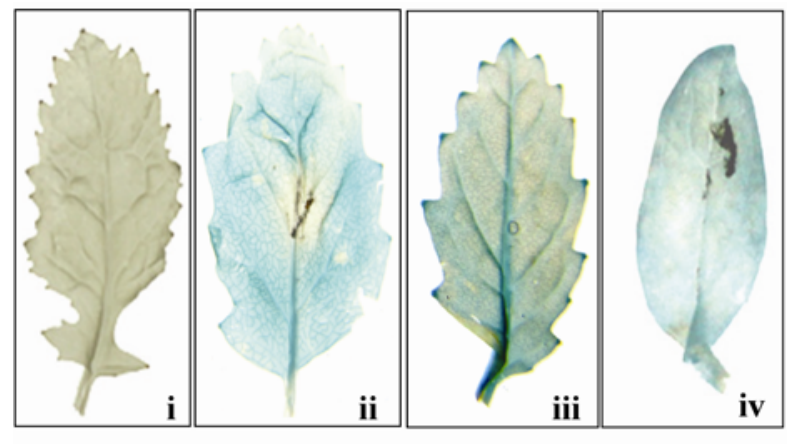

A
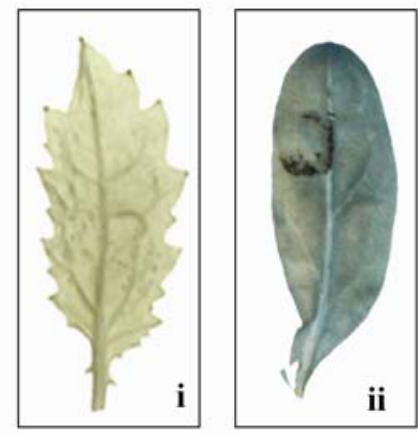

B

Fig. 3. $\beta$-Glucuronidase (GUS) expression after histochemical staining. A, In the leaves of the promoter of $S$. alba glycosyl hydrolase gene (PGH)-GUS transgenic Brassica juncea line 3a. (i) Control; (ii) Alternaria brassicicolachallenged leaf; (iii) $5 \mathrm{mM}$ salicylic acid (SA)-treated leaf; (iv) A. brassicicola inoculation after $1 \mathrm{mM}$ SA treatment. B, In D1-GUS transgenic B. juncea line 2a. (i) Control; (ii) After A. brassicicola challenge.
$5 \mu \mathrm{M} \mathrm{ABA}$, and $5 \mathrm{mM}$ but not $1 \mathrm{mM}$ SA (Fig. 4), reflecting the same expression trend of the $G H$ gene as observed in $S$. alba. To understand the phytohormone-mediated signaling involved in induction of the gene in $S$. alba upon interaction with $A$. brassicicola, further experiments were conducted. The plants were treated with $1 \mathrm{mM}$ SA and, thereafter, the expression of the $G H$ gene was monitored at 24 and 48 hpi with $A$. brassicicola spores. Interestingly, the A. brassicicola-mediated induction of the $G H$ gene, observed earlier at 24 and $48 \mathrm{hpi}$, was completely abolished by SA (Fig. 5). It is an important observation because $1 \mathrm{mM} \mathrm{SA}$ alone did not have any effect on the expression of the gene. Experiments were next performed to test whether SA had similar effect, as observed in $S$. alba, on the pathogen-mediated expression of the $G H$ promoter in the susceptible $B$. juncea background. Contrary to the observation in $S$. alba, $1 \mathrm{mM}$ SA treatment prior to $A$. brassicicola challenge did not have any inhibitory effect on the GUS expression in the PGH-GUS transgenic B. juncea (Fig. 4 ), indicating that the pathogen-mediated induction of the $G H$ promoter was not inhibited by SA in B. juncea.

To get an idea about the hormone signaling triggered upon interaction with $A$. brassicicola, the expression of two important genes-the AOS gene, involved in the jasmonic acid (JA) biosynthetic pathway; and PR1, a marker of the SA response-were monitored in $S$. alba and $B$. juncea after $A$. brassicicola infection by real-time RT-PCR. In $S$. alba, the $A O S$ gene was found to be upregulated at all time points post infection whereas, in B. juncea, the AOS gene was heavily downregulated (Fig. 6A). In contrast, the expression of the $P R l$ gene was far more pronounced in $B$. juncea compared with $S$. alba (Fig. 6B). The effect of low concentration of SA $(1 \mathrm{mM})$ on the pathogen-induced expression of these genes was studied in a manner similar to that done for the $G H$ gene in $S$. alba. The pathogen-mediated enhanced expression of the $A O S$ gene was reduced to approximately the basal level in the presence of SA (Fig. 6A), indicating the negative effect of SA on the A. brassicicola-induced JA biosynthetic gene. In contrast, in $S$. alba, the level of PRI gene expression on challenge with $A$.

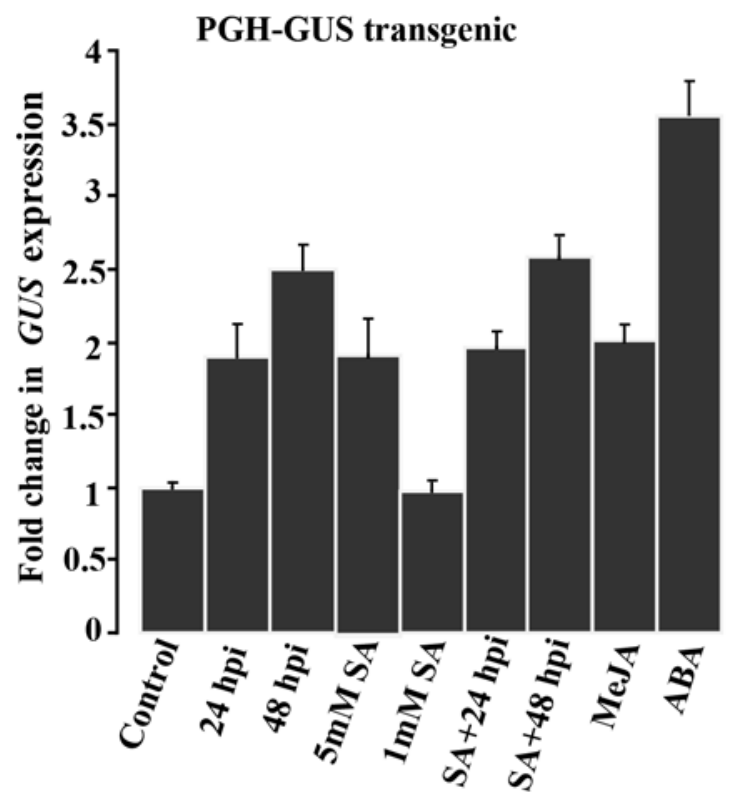

Fig. 4. Real-time quantification of the $\beta$-glucuronidase (GUS) transcript in promoter of $S$. alba glycosyl hydrolase gene (PGH)-GUS transgenic Brassica juncea line $3 \mathrm{a}$ after challenge with Alternaria brassicicola and in the presence of phytohormones. The uninoculated or untreated transgenic plants of the same line at the corresponding time points were used as the controls. In all treatments, relative changes of expression of the gene were plotted with respect to the respective controls (values one) which, therefore, has been represented only once. Bars represent mean \pm standard error of three biological replicates. 
brassicicola was found to be almost similar with the $1 \mathrm{mM} \mathrm{SA}$ mediated expression (Fig. 6B).

Deletion analysis of the $\boldsymbol{G H}$ promoter. To identify the cis elements that were involved in the hormonal response and that imparted inducibility to the $G H$ gene during the interaction with A. brassicicola, deletion analysis of the promoter was performed. Two deletion constructs were generated, based on the distribution of the motifs identified with the PLACE software. The promoter regions from -780 to -1 bp in the first deletion (D1) and from -387 to -1 bp in the second deletion (D2) were amplified by PCR and fused to the GUS gene of pCAMBIA 1301 (Fig. 7). Transgenic B. juncea plants were confirmed by PCR (Supplemental Figures 5 and 6). Expression of the $G U S$ gene was monitored histochemically in the transgenic plants after challenge with $A$. brassicicola. The leaves of the D1-GUS transgenic plants showed GUS staining (Fig. 3B), whereas the leaves of the D2-GUS plants showed no GUS staining. The expression of the GUS gene was further quantified using real-time RT-PCR. The transgenic plants that showed little variation in the GUS expression on A. brassicicola challenge were considered for further analysis. The data shown here are from one such line. In all cases, the untreated transgenic plants corresponding to each deletion were considered to be the controls. The expression of the GUS gene in the D1GUS transgenic line was approximately equal to that of the PGHGUS line during the interaction with A. brassicicola (Fig. 8A). However, in a comparable situation in the D2-GUS plants, the GUS gene was not induced (Fig. 8B). In the D1-GUS plants, exogenous MeJA induced the reporter gene to the same level as in the PGH-GUS plants whereas, in the D2-GUS plants, the GUS gene remained uninduced. In the presence of ABA, no significant induction of the GUS gene was found in either the D1-GUS or D2-GUS plants. In the presence of $5 \mathrm{mM}$ SA, the GUS gene was not induced in the D2-GUS plants compared with the PGH-GUS and D1-GUS transgenic lines (Fig. 8A and B). Therefore, the results indicate that the major JA- and SA-responsive motifs were located in the region between the D1 and D2 deletions, whereas the major ABA-responsive motif was present in the PGH but not the $\mathrm{D} 1$ deletion.

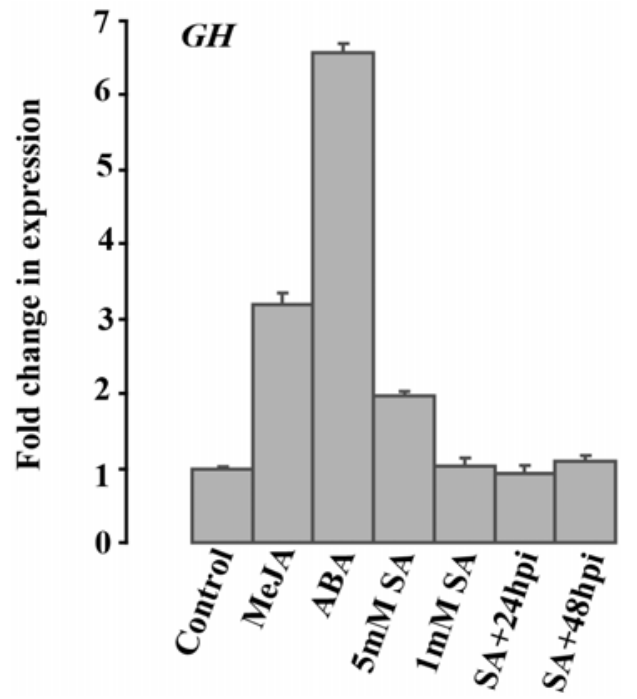

Fig. 5. Expression analysis of the Sinapis alba glycosyl hydrolase $(G H)$ gene in the presence of different phytohormones such as methyl jasmonate (MeJA), abscisic acid (ABA), and salicylic acid (SA) and Alternaria brassicicola inoculation after $1 \mathrm{mM}$ SA treatment using real-time reverse-transcription polymerase chain reaction. Control leaf samples were collected at the respective time points from plants without phytohormone treatment or A. brassicicola challenge. In all treatments, relative changes of expression of the gene were plotted with respect to the respective controls (values one) which therefore has been represented only once. Bars represent mean \pm standard error of three biological replicates.
Detection of functional JA- and ABA-responsive motifs in the $G H$ promoter through deletion analysis in $N$. tabacum. The motif scan with the PLACE prediction software showed the presence of multiple motifs for each hormone up to the D2 region. However, it has been reported that, in a functional promoter, the "flanking sequences" in addition to the "core elements" are very important for the recognition of the cis-regulatory elements by the transcription factors (38). It is also evident from our analysis of the cis-regulatory elements of the $G H$ promoter that the flanking nucleotide sequences of the core elements vary a lot. Therefore, in order to identify the exact phytohormones-responsive cis elements responsible for the induction of the gene, deletion analysis of the region from $-1,096$ to $-388 \mathrm{bp}$ was conducted in $N$. tabacum. The CSG promoter region $(-1,096$ to $-388 \mathrm{bp})$
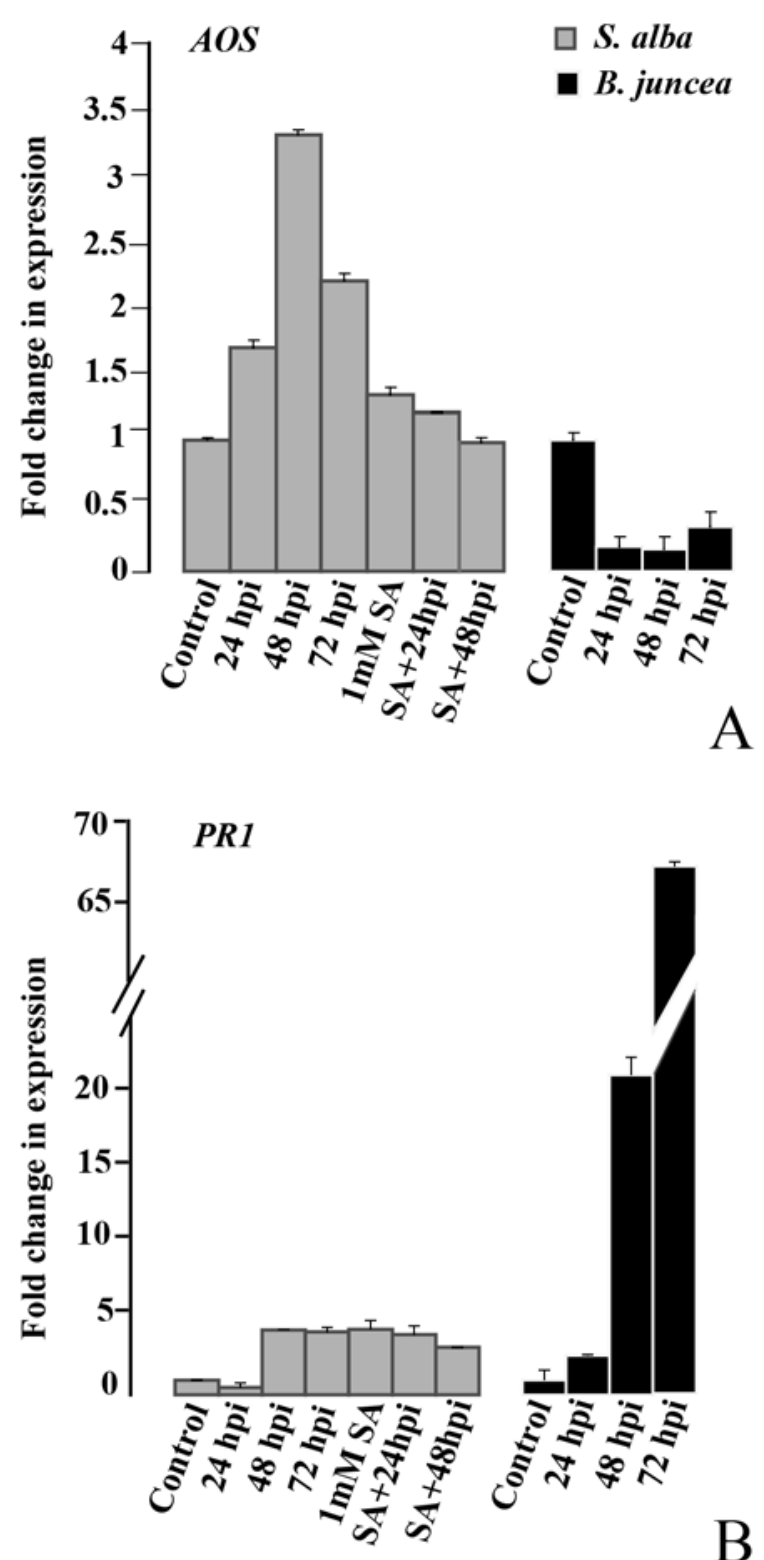

B

Fig. 6. Real-time reverse-transcription polymerase chain reaction expression analysis of the $\mathbf{A}$, Allene oxide synthase $(A O S)$ and $\mathbf{B}$, pathogenesis-related $(P R) 1$ genes in Sinapis alba and Brassica juncea at different hours post inoculation (hpi) with Alternaria brassicicola spores and after salicylic acid (SA) treatment prior to the A. brassicicola challenge. The $S$. alba and B. juncea leaf samples at the respective time points, treated with only water instead of the spores or hormone, were considered as controls. In all treatments, relative changes of expression of the genes were plotted with respect to the respective controls (values one) which, therefore, has been represented only once. Bars represent mean \pm standard error of three biological replicates. 
contained three MYB binding sites, three ABRE elements, two T/G boxes, and seven GT-1 binding sites. In comparison, the $\mathrm{F}_{1} \mathrm{SG}$ deletion ( -780 to $-388 \mathrm{bp}$ ) contained two T/G boxes, three ABRE motifs, and four GT-1 factor binding sites, and the $\mathrm{F}_{2} \mathrm{SG}$ deletion ( -607 to $-388 \mathrm{bp}$ ) contained only one T/G box, two ABRE motifs, and three GT-1 factor binding sites. The three deletions were amplified and fused to the 46-bp CaMV $35 \mathrm{~S}$ minimal promoter by PCR ligation (Fig. 9). The chimeric promoters were fused with the GUS gene in pCAMBIA 1301 and introduced into $N$. tabacum by agroinfiltration. The induction of the GUS gene was monitored by real-time RT-PCR in the infiltrated leaves.

Except for the CSG-MP-GUS construct-harboring plants, the other deletion construct-containing plants failed to induce $G U S$ expression after exogenous ABA application (Fig. 10A to C). These results indicate that the functional ABA motifs in this promoter are probably the MYB transcription-factor binding sites ( $-933,-925$, and -829 bp), present only in the CSG-MP construct, although a number of ABA-responsive motifs were identified through the PLACE software. However, in the presence of MeJA, enhanced GUS expression was found in both the CSGMP-GUS- and $\mathrm{F}_{1} \mathrm{SG}-\mathrm{MP}-\mathrm{GUS}$-containing leaves but not the $\mathrm{F}_{2}$ SG-MP-GUS-containing leaves (Fig. 10A to C). These data indicated that, of the two T/G motifs, the one at $-744 \mathrm{bp}$ is responsible for the JA-mediated induction. In the presence of $5 \mathrm{mM}$ SA, the expression of the GUS gene was reduced in the $\mathrm{F}_{1}$ SG-MP-GUS and further reduced to the basal level in the $\mathrm{F}_{2}$ SG-MP-GUS plants, showing that the major SA-responsive motifs were distributed in the promoter region between $-1,096$ and -780 bp (Fig. 10A to C). These results prove that the upstream region of the $S$. alba $G H$ gene was able to confer inducibility to the $35 \mathrm{~S}$ minimal promoter, even in the heterologous system of N. tabacum.

\section{DISCUSSION}

The vast family of GH comprises proteins that form an integral part of many important physiological processes in plants, including plant defense. Several PR proteins, such as PR2, PR3, PR4, and PR11, which are induced during the plant defense response against different pathogens, are GHs (33). In our study, a family 3 $G H$ gene was found to be upregulated in the resistant plant $S$. alba from an early stage of encounter with the necrotrophic fungal pathogen A. brassicicola. The gene was maintained at an elevated level even during the late phase of the disease progression (up to 72 hpi). On the other hand, the corresponding homologue in the susceptible $B$. juncea plant showed very slight change after challenge with the pathogen.

Exploration into the induction mechanism of the $S$. alba $G H$ gene showed that the gene could be induced by exogenous

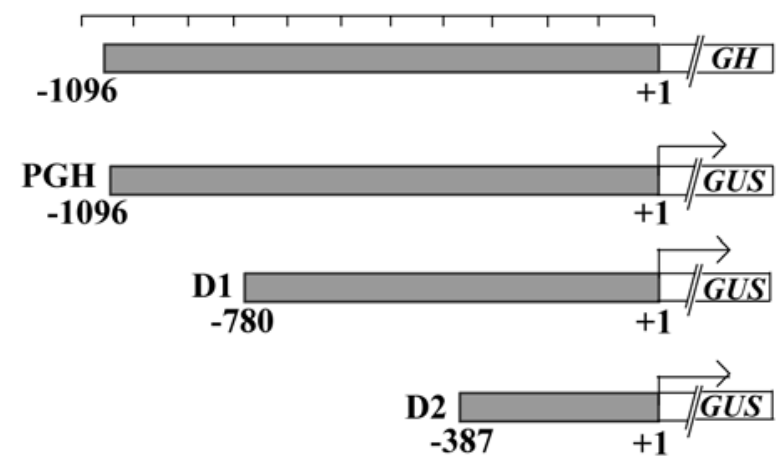

Fig. 7. Schematic representation of the 1,096-bp promoter of the Sinapis alba glycosyl hydrolase $(G H)$ gene $(\mathrm{PGH})$ and the $5^{\prime}$ deletions (D1 and D2) after being fused to the $\beta$-glucuronidase $(G U S)$ gene in the binary vector pCAMBIA 1301.Nucleotide positions shown are relative to the ATG start codon. application of JA, ABA, and SA phytohormones, which are known to be involved in various plant defense responses (4). The phytohormone JA is known to play an important role in the resistance response against $A$. brassicicola from the studies of the JA-insensitive mutant coil of Arabidopsis, which shows a high level of susceptibility compared with wild-type Col-0 plants $(12,21,22,49)$. In our study, deletion analyses of the $\mathrm{GH}$ promoter in transgenic B. juncea and $N$. tabacum showed that the $G H$ promoter contained a functional JA-responsive cis-element in the form of one of the $T / G$ boxes. This motif has been previously reported to be present in the promoters of important JA-responsive defense-related genes such as $P I-I I$ and $L A P$ of potato and tomato $(10,28)$. In addition to the above finding, the enhanced expression of the JA biosynthetic gene AOS together with the $G H$ gene in $S$. alba, after challenge with A. brassicicola, points to the probability of the presence of a common triggering mechanism.

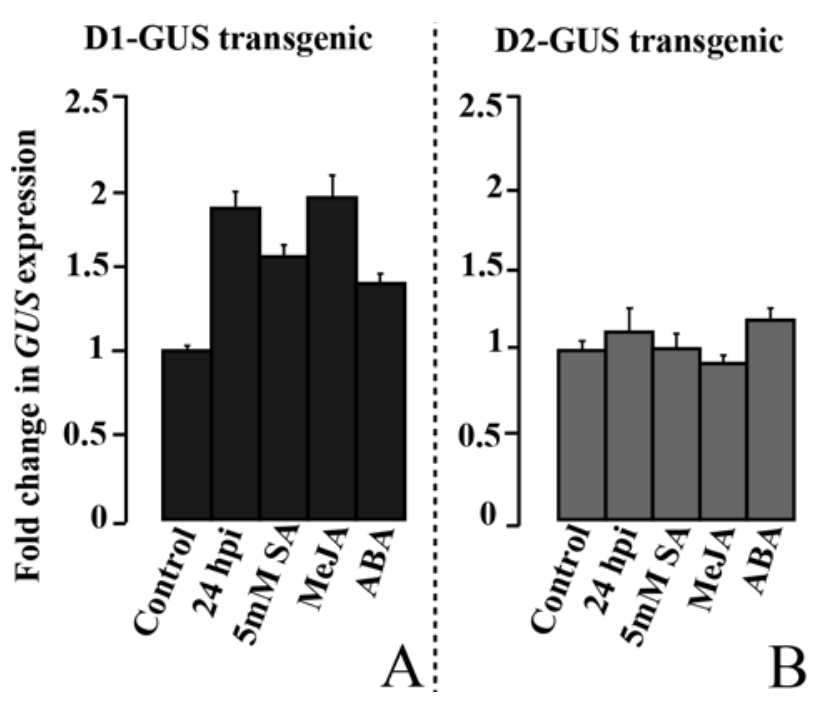

Fig. 8. Real-time quantification of the $\beta$-glucuronidase (GUS) transcript in the A, D1-GUS and B, D2-GUS transgenic Brassica juncea plants after challenge with Alternaria brassicicola and after exogenous phytohormone application. The untreated D1-GUS and D2-GUS transgenic plants at the corresponding time points were used as the respective controls. Bars represent mean \pm standard error of three biological replicates. In all treatments, relative changes of expression of the gene were plotted with respect to the respective controls (values one) which, therefore, has been represented only once.

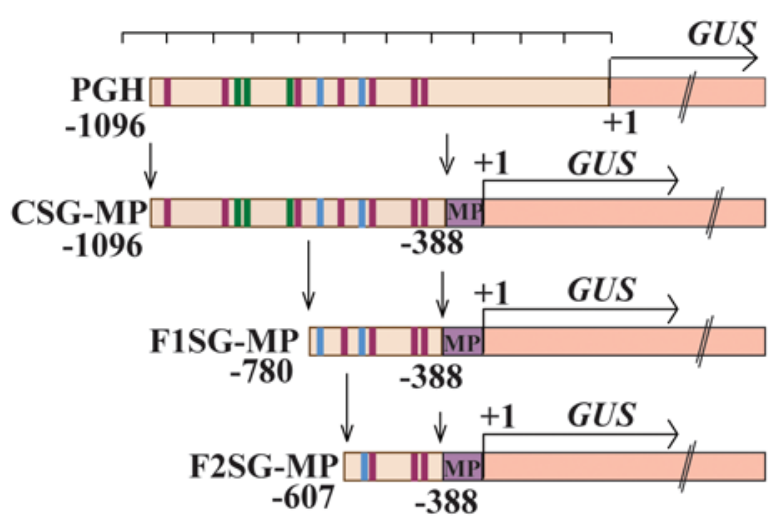

- GT-1 $\because$ MYB $\because$ T/G box

Fig. 9. Schematic representation of the deletion construct of the Sinapis alba glycosyl hydrolase $(G H)$ promoter used for the Agrobacterium-mediated transient expression study in Nicotiana tabacum leaves. The $5^{\prime}$ deletions were fused with the 46-bp minimal Cauliflower mosaic virus (CaMV) $35 \mathrm{~S}$ promoter (MP) (CSG-MP, F1SG-MP, and F2SG-MP) and fused with the $\beta$ glucuronidase $(G U S)$ gene in the binary vector pCAMBIA. 
ABA is emerging as another contributor to the resistance against this necrotroph from recent studies $(50,51)$. The increased susceptibility of ABA mutants of Arabidopsis toward A. brassicicola point to the important role of $\mathrm{ABA}$ in the resistance response. ABA was found to act by promoting the biosynthesis of JA (3). The $S$. alba $G H$ gene showed huge upregulation in the presence of $\mathrm{ABA}$ and the deletion analysis showed that the MYB recognition site was the main ABA-responsive cis-element present in the promoter. In a previous study, this motif, along with the MYC factor binding sites, has been shown to be responsible for the drought and ABA inducibility of the Arabidopsis dehydrationresponsive gene, $R D 22(1,2)$.

In addition to that, our results showed that this gene was also induced in the presence of exogenous SA. However, the inhibition of the expressions of the $G H$ and $A O S$ genes by the application of $1 \mathrm{mM}$ SA prior to A. brassicicola challenge in $S$. alba clearly demonstrates the antagonistic effect of SA on the pathogen induced expression of these genes. This observation fits very well with the study of Spoel et al. (47), where they documented the strong inhibitory effect of exogenous SA on the JA-mediated resistance response during the Arabidopsis-A. brassicicola interaction. Therefore, presence of functional JA- and ABA-responsive cis-elements in the promoter indicate that these two phytohormones are probably involved in the induction of the $G H$ gene in $S$. alba.

The $S$. alba $G H$ promoter was also induced in the susceptible $B$. juncea background after challenge with $A$. brassicicola but the level of induction in the two plants were different. Dissection of the induction mechanism in B. juncea showed that the elimination of the ABA-responsive elements in the deletions, which resulted in the reduction of the ABA-mediated induction of the promoter, did not have any effect on the pathogen-mediated induction of the $G H$ promoter in susceptible B. juncea. Interestingly, contrary to the observation in $S$. alba, SA treatment prior to infection with the pathogen did not have any negative effect on the expression of the promoter in B. juncea. Thus, this important finding indicates that JA is probably not involved in the induction of the $G H$ promoter in B. juncea during interaction with A. brassicicola because SA, known to be antagonistic to JA responses, has no adverse effect on the induction of the promoter. Additionally, the simultaneous huge upregulation of the PR1 gene and the downregulation of the $A O S$ gene indicate that, in $B$. juncea, the pathogen-mediated induction of the GUS gene, under the control of the $G H$ promoter, shares commonness with the expression of the PR1 gene but not the $A O S$ gene.

The antagonistic role played by SA in the resistance response against this necrotroph is a very well-known fact. The enhanced susceptibility of the pmr4 mutant of Arabidopsis, which expresses PR1 constitutively, to $A$. brassicicola demonstrates the negative effect of SA (19). SA-responsive elements in the S. alba $G H$ promoter were found to be present in the form of several GT-1 factor binding sites. The same motif present in the promoter of the PR-1a gene of $N$. tabacum was reported to be involved in the SA response of the promoter (14). Therefore, the above results show that the transcriptional regulation of the $G H$ gene is quite interesting and the induction mechanisms in resistant $S$. alba and susceptible $B$. juncea is mediated by different phytohormone responses. In this context, it is to be mentioned that the estimation of the endogenous phytohormone levels shows enhanced ABA and JA levels in resistant $S$. alba and enhanced SA level in susceptible $B$. juncea upon challenge with $A$. brassicicola (data not shown). This very well supports our finding of the differences in the phytohormonal regulations during the induction of the GH gene in $S$. $a l b a$ and $B$. juncea upon infection.

The $S$. alba $G H$ gene shares high identities with other family 3 $G H$ homologues from Arabidopsis thaliana, A. lyrata, and species such as Ricicnus communis, Vitis vinifera, and Medicago truncatula. Multiple alignment of the predicted amino acid sequence of the $S$. alba $G H$ gene with other family $3 \mathrm{GH}$ proteins of $A$. thaliana and A. lyrata is shown in Supplemental Figure 7.

The family $3 \mathrm{GHs}$, which include the enzymes $\beta$-glucosidase, $\beta$-xylosidase, and $\beta$ - $N$-acetylhexosaminidase, act on diverse substrates and are involved in many important biological functions. In plants, the GH3 enzymes are associated with the recycling or turnover of cell-wall components, which are very important steps during development as well as defense responses of plants. The role of these enzymes in plant defense is an emerging area. This class of enzymes is also capable of modulating the signaling of plant defense responses by altering or modifying the structure of fungal elicitors, such as $\beta$-1,3-glucosides and $N$-acetylchitooligomers, which are potential substrates for this group of enzymes (55). Therefore, our report of the significant differential expression of a putative $\mathrm{GH} 3$ gene (a $\beta$-glucosidase) in resistant $S$. alba in comparison with susceptible $B$. juncea after challenge with the fungal pathogen Alternaria brassicicola is an important finding in this context. Isolation of the full-length cDNA se-
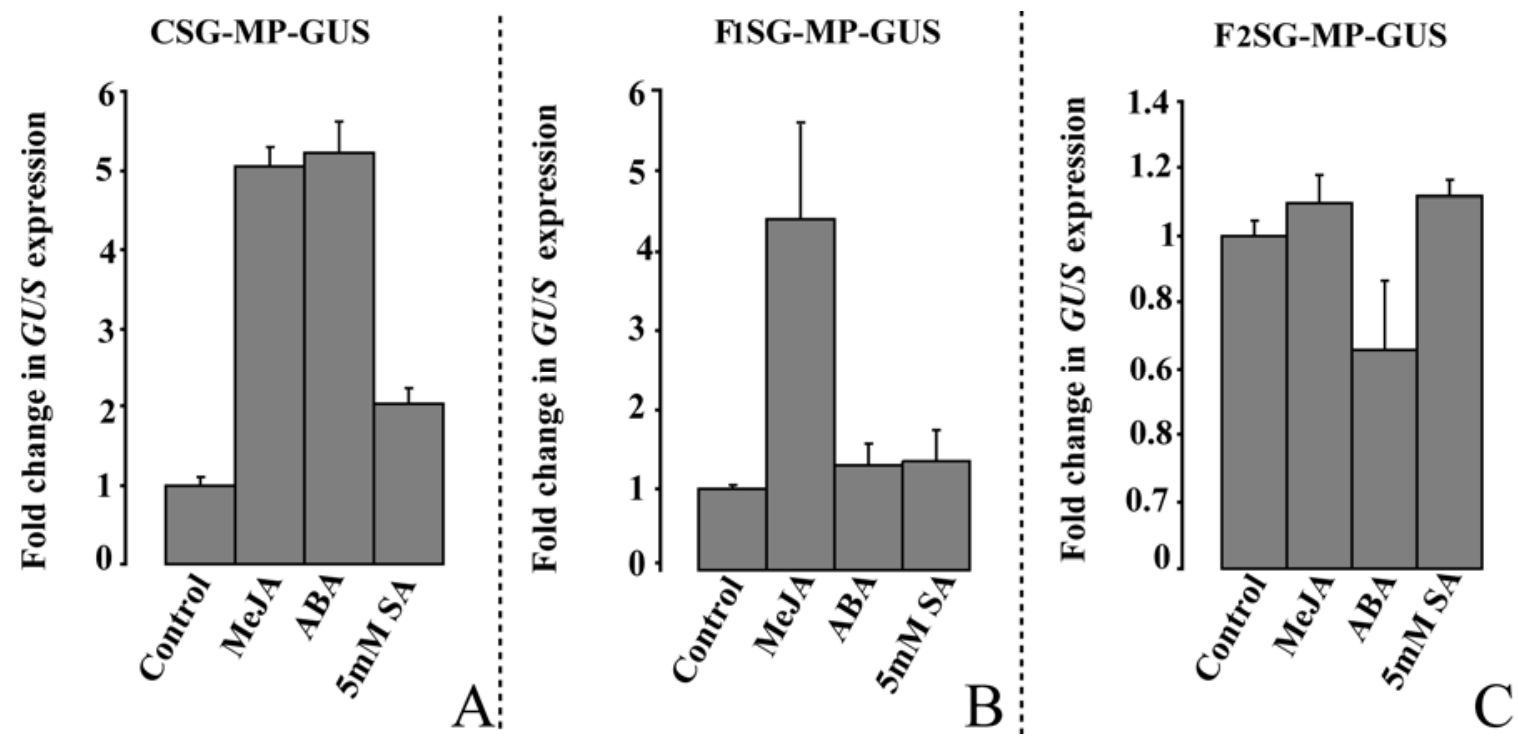

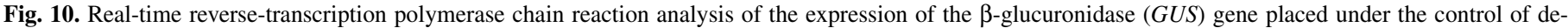

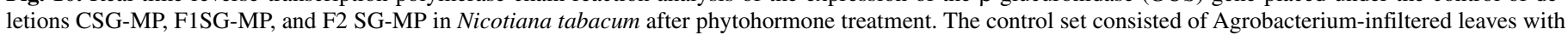
the respective constructs after treatment with solvents without the supplemented hormones. The mean \pm standard error of four biological replicates is represented. 
quence of the gene in this work will further enable us to elucidate the exact function of the gene. In addition to plants, the family 3 GH enzymes are also produced by plant-pathogenic bacteria and fungi. The pathogens, with the help of these enzymes, either alone or in combination with other GHs, modify the plant-derived compounds which play important roles in defense. Enzymes such as avenacinase and tomatinase produced by phytopathogenic fungi to deglycosylate and detoxify saponins of the host plants belong to the GH3 class of enzymes which are used by the pathogens during infection $(11,34)$.

Identification of this promoter, which is induced in both the resistant as well as susceptible backgrounds after challenge with A. brassicicola, is a very good candidate to be used in the future biotechnological programs for expression of desired genes to control the pathogen. Furthermore, the above study shows that $A$. brassicicola-mediated induction of the $G H$ promoter in the resistant and susceptible backgrounds was through different mechanisms. This understanding could be used in the future to maneuver the faulty responses operating in susceptible $B$. juncea plants and prevent the huge yield losses incurred because of the black-spot disease. Therefore, knowledge of the hormonal responses operating in resistant $S$. alba is one step forward toward the development of resistant oilseed mustard using gene manipulation techniques.

\section{ACKNOWLEDGMENTS}

We thank the Council of Scientific and Industrial Research and the Department of Biotechnology for providing financial support, the Director of Bose Institute for encouragement and support, and Professor S. Das for constant help and guidance.

\section{LITERATURE CITED}

1. Abe, H., Urao, T., Ito, T., Seki, M., Shinozaki, K., and YamaguchiShinozaki, K. 2003. Arabidopsis AtMYC2 (bHLH) and AtMYB2 (MYB) function as transcriptional activators in abscisic acid signaling. Plant Cell 15:63-78.

2. Abe, H., Yamaguchi-Shinozaki, K., Urao, T., lwasaki, T., Hosokawa, D., and Shinozaki, K. 1997. Role of Arabidopsis MYC and MYB homologs in drought and abscisic acid-regulated gene expression. Plant Cell 9:18591868 .

3. Adie, B. A. T., Perez-Perez, J., Perez-Perez, M. M., Godoy, M., SanchezSerrano, J. J., Schmelz, E. A., and Solano, R. 2007. ABA is an essential signal for plant resistance to pathogens affecting JA biosynthesis and the activation of defenses in Arabidopsis. Plant Cell 19:1665-1681.

4. Bari, R., and Jones, J. D. G. 2009. Role of plant hormones in plant defence responses. Plant Mol. Biol. 69:473-488

5. Berger, S., Papadopoulos, M., Schreiber, U., Kaiser, W., and Roitsch, T. 2004.Complex regulation of gene expression, photosynthesis and sugar levels by pathogen infection in tomato. Physiol. Plant. 122:419-428.

6. Berger, S., Sinha, A. K., and Roitsch, T. 2007. Plant physiology meets phytopathology: Plant primary metabolism and plant-pathogen interactions. J. Exp. Bot. 58:4019-4026.

7. Boller, T., and He, S.Y. 2009. Innate immunity in plants: an arms race between pattern recognition receptors in plants and effectors in microbial pathogens. Science 324:742-744.

8. Bolouri Moghaddam, M. R., and Van den Ende, W. 2012. Sugars and plant innate immunity, J. Exp. Bot. Online publication. doi:10.1093/jxb/ers129

9. Bolton, M. D. 2009. Primary Metabolism and plant defense-fuel for the fire? Mol. Plant-Microbe Interact. 22:487-497.

10. Boter, M., Ruíz-Rivero, O., Abdeen, A., and Prat, S. 2004. Conserved MYC transcription factors play a key role in jasmonate signalling both in tomato and Arabidopsis. Genes Dev. 18:577-1591.

11. Bowyer, P., Clarke, B. R., Lunness, P., Daniels, M. J., and Osbourn, A. E. 1995. Host range of a plant pathogenic fungus determined by a saponin detoxifying enzyme. Science 267:371-374.

12. Broglie, K., Chet, I., Holliday, M., Cressman, R., Biddle, P., Knowlton, S., Brown, R. L., Kazan, K., McGrath, K. C., Maclean, D. J., and Manners, J. M. 2003. A Role for the GCC-Box in jasmonate-mediated activation of the PDF1.2 gene of Arabidopsis. Plant Physiol. 132:10201032 .

13. Buchanan-Wollaston, V., Page, T., Harrison, E., Breeze, E., Lim, P. O., Nam, H. G., Lin, J., Wu, S., Swidzinski, J., Ishizaki, K., and Leaver, C.
2005. Comparative transcriptome analysis reveals significant differences in gene expression and signalling pathways between developmental and dark/starvation-induced senescence in Arabidopsis. Plant J. 42:567-585.

14. Buchel, A. S., Brederode, F. T., Bol, J. F., and Linthorst, H. J. M. 1999. Mutation of GT-1 binding sites in the Pr-1A promoter influences the level of inducible gene expression in vivo. Plant Mol. Biol. 40:387-396.

15. Chou, H., Bundock, N., Rolfe, S., and Scholes, J. 2000. Infection of Arabidopsis thaliana leaves with Albugo candida causes a reprogramming of host metabolism. Mol. Plant Pathol. 1:99-113.

16. Dutta, I., Majumder, P., Saha, P., Ray, K., and Das, S. 2005. Constitutive and phloem specific expression of Allium sativum leaf agglutinin (ASAL) to engineer aphid (Lipaphis erysimi) resistance in transgenic Indian mustard (Brassica juncea). Plant Sci. 169:996-1007.

17. Faure, D. 2002. The family-3 glycoside hydrolases: from housekeeping functions to host-microbe interactions. Appl. Environ. Microbiol. 68:1485-1490

18. Flor, H. H. 1971. Current status of the gene-for-gene concept. Annu. Rev. Phytopathol. 9:275-296

19. Flors, V., Ton, J., Doorn, R., Jakab, G., Garcia-Agustın, P., and MauchMani, B. 2007. Interplay between JA, SA and ABA signalling during basal and induced resistance against Pseudomonas syringae and Alternaria brassicicola. Plant J. 54:81-92.

20. Ghose, K., Dey, S., Barton, H., Loake, G. J., and Basu, D. 2008. Differential profiling of selected defence-related genes induced on challenge with Alternaria brassicicola in resistant white mustard and their comparative expression pattern in susceptible India mustard. Mol. Plant Pathol. 9:763-775.

21. Glazebrook, J. 2001. Genes controlling expression of defense responses in Arabidopsis. Curr. Opin. Plant. Biol. 4:301-308.

22. Glazebrook, J. 2005. Contrasting mechanisms of defense against biotrophic and necrotrophic pathogens. Annu. Rev. Phytopathol. 43:205227.

23. Hammond-Kosack, K. E., and Jones, J. D. G. 1997. Plant disease resistance genes. Annu. Rev. Plant Physiol. Plant Mol. Biol. 48:2-45.

24. Heath, M. C. 2000. Nonhost resistance and nonspecific plant defenses. Curr. Opin. Plant Biol. 3:315-319.

25. Henrissat, B., and Bairoch, A. 1996. Updating the sequence-based classification of glycosyl hydrolases. Biochem. J. 316:695-696.

26. Herbers, K., Takahata, Y., Melzer, M., Mock, H. P., Hajirezaei, M., and Sonnewald, U. 2000. Regulation of carbohydrate partitioning during the interaction of Potato virus $Y$ with tobacco. Mol. Plant Pathol. 1:51-59.

27. Kim, J., Olek, A. T., and Carpita, N. 2000. Cell wall and membraneassociated exo- $\beta$-D-glucanases from developing maize seedlings. Plant Physiol. 123:471-485.

28. Kim, S., Choi, J., Costa, M., and An, G. 1992. Identification of G-Box sequence as an essential element for methyl jasmonate response of potato proteinase inhibitor ii promoter. Plant Physiol. 99:627-631.

29. Leon, P., and Sheen, J. 2003. Sugar and hormone connections. Trends Plant Sci. 8:110-116

30. Lipka, V., Dittgen, J., Bednarek, P., Bhat, R., Wiermer, M., Stein, M., Landtag, J., Brandt, W., Rosahl, S., Scheel, D., Llorente, F., Molina, A., Parker, J., Somerville, S., and Schulze-Lefert, P. 2005. Pre- and postinvasion defenses both contribute to nonhost resistance in Arabidopsis. Science 310:1180-1183.

31. Livak, K. J., and Schmittgen, T. D. 2001. Analysis of relative gene expression data using real-time quantitative PCR and the $2^{-\Delta \Delta C}$ method. Methods 25:402-408.

32. Maleck, K., Levine, A., Eulgem, T., Morgen, A., Schmid, J., Lawton, K., Dangl, J. L., and Dietrich, R. A. 2000. The transcriptome of Arabidopsis thaliana during systemic acquired resistance. Nat. Genet. 26:403-410.

33. Minic, Z. 2008. Physiological roles of plant glycoside hydrolases. Planta 227:723-740.

34. Osbourn, A., Bowyer, P., Lunness, P., Clarke, B., and Daniels, M. 1995. Fungal pathogens of oat roots and tomato leaves employ closely related enzymes to detoxify different host plant saponins. Mol. Plant-Microbe Interact. 8:971-978.

35. Park, H. C., Kim, M. L., Kang, Y. H., Jeon, J. M., Yoo, J. H., Kim, M. C., Park, C. Y., Jeong, J. C., Moon, B. C., Lee, J. H., Yoon, H. W., Lee, S. H., Chung, W. S., Lim, C. O., Lee, S. Y., Hong, J. C., and Cho, M. J. 2004 Pathogen- and NaCl-induced expression of the SCaM-4 promoter is mediated in part by a GT-1 Box that interacts with a GT-1-Like transcription factor. Plant Physiol. 135:2150-2161.

36. Pruss, G. J., Nester, E. W., and Vance, V. 2008. Infiltration with Agrobacterium tumefaciens induces host defense and developmentdependent responses in the infiltrated zone. Mol. Plant-Microbe Interact. 21:1528-1538

37. Roitsch, T., Balibrea, M. E., Hofmann, M., Proels, R., and Sinha, A. K. 2003. Extracellular invertase: Key metabolic enzyme and PR protein. J. Exp. Bot. 54:513-524.

38. Rushton, P. J., Reinstädler, A., Lipka, V., Lippok, B., and Somssich, I. E. 
2002. Synthetic plant promoters containing defined regulatory elements provide novel insights into pathogen- and wound-induced signaling. Plant Cell 14:749-762.

39. Rushton, P. J., and Somssich, I. E. 1998. Transcriptional control of plant genes responsive to pathogens. Curr. Opin. Plant Biol. 1:311-315.

40. Rushton, P. J., Torres, J. T., Parniske, M., Wernert, P., Hahlbrock, K., and Somssich, I. E. 1996. Interaction of elicitor-induced DNA binding proteins with elicitor response elements in the promoters of parsley PR1 genes. EMBO J. 15:5690-5700.

41. Sa, Q., Wang, Y., Zhang, L., and Sun, Y. 2003. The promoter of an antifungal protein gene from Gastrodia elata confers tissue-specific and fungus-inducible expression patterns and responds to both salicylic acid and jasmonic acid. Plant Cell Rep. 22:79-84.

42. Sambrook, J., Fritsch, E. F., and Maniatis, T. 1989. Molecular Cloning: A Laboratory Manual, 2nd ed. Cold Spring Harbor Laboratory Press, Cold Spring Harbor, NY.

43. Scharte, J., Schon, H., and Weis, E. 2005. Photosynthesis and carbohydrate metabolism in tobacco leaves during an incompatible interaction with Phytophthora nicotianae. Plant Cell Environ. 28:1421-1435.

44. Schenk, P. M., Kazan, K., Wilson, I. W., Anderson, J. P., Richmond, T., Somerville, S. C., and Manners, J. M. 2000. Coordinated plant defense responses in Arabidopsis revealed by microarray analysis. Proc. Natl. Acad. Sci. USA 97:11655-11660.

45. Schenk, P. M., Kazan, K., Manners, J. M., Anderson, J. P., Simpson. R.S, Wilson, I. W, Somerville, S. C., and Maclean, D. J. 2003. Systemic gene expression in Arabidopsis during an incompatible interaction with Alternaria brassicicola. Plant Physiol. 132:999-1010.

46. Schlumbaum, A., Mauch, F., Vogeli, U., and Boller, T. 1986. Plant chitinases are potent inhibitors of fungal growth. Nature 324:365-367.

47. Spoel, S. H., Johnson, J. S., and Dong, X. 2007. Regulation of tradeoffs between plant defences against pathogens with different lifestyles. Proc. Natl. Acad. Sci. USA 104:18842-18847.

48. Swarbrick, P. J., Schulze-Lefert, P., and Scholes, J. D. 2006. Metabolic consequences of susceptibility and resistance in barley leaves challenged with powdery mildew. Plant Cell Environ. 29:1061-1076.

49. Thomma, B. P. H. J., Eggermont, K., Penninckx, I. A. M. A., MauchMani, B., Vogelsang, R., Cammue, B. P. A., and Broekaert, W. F. 1998. Separate jasmonate-dependent and salicylate-dependent defense-response pathways in Arabidopsis are essential for resistance to distinct microbial pathogens. Proc. Natl. Acad. Sci. USA 95:15107-15111.

50. Ton, J., Jakab, G., Toquin, V., Flors, V., Iavicoli, A., Maeder, M. N., Metraux, J. P., and Mauch-Mani, B. 2005. Dissecting the beta aminobutyric acid-induced priming phenomenon in Arabidopsis. Plant Cell 17:987-999.

51. Ton, J., and Mauch-Mani, B. 2004. $\beta$-Amino-butyric acid-induced resistance against necrotrophic pathogens is based on ABA-dependent priming for callose. Plant J. 38:119-130.

52. van Doorn, W. G. 2008. Is the onset of senescence in leaf cells of intact plants due to low or high sugar levels? J. Exp. Bot. 59:1963-1972.

53. Wright, D., Baldwin, B., Shephard, M., and Scholes, J. 1995. Source-sink relationships in wheat leaves infected with powdery mildew. Physiol. Mol. Plant Pathol. 47:237-253.

54. Wu, C., and Bradford, K. J. 2003. Class I chitinase and $\beta$-1,3-glucanase are differentially regulated by wounding, methyl jasmonate, ethylene, and gibberellin in tomato seeds and leaves. Plant Physiol. 133:263-273.

55. Yamaguchi, T., Yamada, A., Hong, N., Ogawa, T., Ishii, T., and Shibuya, N. 2000. Differences in the recognition of glucan elicitor signals between rice and soybean: $\beta$-glucan fragments from the rice blast disease fungus Pyricularia oryzae that elicit phytoalexin biosynthesis in suspensioncultured rice cells. Plant Cell 12:817-826. 